\title{
REFERENCES
}

Brown G. W. \& Harris T. (1978) Social origins of depression: a study of psychiatric disorders in women. Tavistock, London.

Kenyon F. E. (1976) Hypochondriacal states British. Journal of Psychiatry 129, 1-14.

\section{Delays to thrombolytic treatment following acute myocardial infarction}

Sir,

We noted with interest the recent article by Mr J. P. Saetta and colleagues on the role of the A\&E department in delays to thrombolytic treatment following acute myocardial infarction (Saetta, 1990). We recently audited admissions, over a 1-month period, to the Cardiac Monitoring Unit at Hull Royal Infirmary from the Accident and Emergency Department. Of the 40 admissions only five underwent thrombolysis; however all five had transit times in our department of less than $35 \mathrm{~min}$ compared to the overall average of $64 \mathrm{~min}$. Early recognition of a patient with a typical presentation of a myocardial infarction with ECG abnormality allows 'fast-tracking' to the Cardiac Monitoring Unit for early thrombolysis.

While Saetta et al. have carefully documented the transfer times for patients from home to Cardiac Monitoring Unit and have referred to delays in presentation, to fully assess this situation we must also examine delays to thrombolysis after transfer to the Cardiac monitoring unit. In two out of our five cases undergoing thrombolysis further delays of $60-90 \mathrm{~min}$ occurred after admission to the Cardiac Monitoring Unit. Both these patients had ST segment elevation.

This type of audit provides useful information, which if presented at joint meetings with the relevant specialities can lead to suggestions for improvements in the management of patients. The audit can then later be repeated to assess the effectiveness of any changes initiated.

G. JOHNSON \& M. WILLIAMS

Hull Royal Infirmary

Hull

\section{REFERENCES}

Saetta J. P., Quinton D. P., DaCruz D. \& Barnes M. (1990) Delay in thrombolytic treatment in acute myocardial infarction: the role of the accident and emergency department. Archives of Emergency Medicine 7, 206-211 